\title{
Association between polyneuritis and multiple sclerosis
}

\author{
C. FORRESTER A NDR. G. LASCELLES \\ From the Department of Neurology, Manchester Royal Infirmary, Manchester
}

SUMMARY We report two cases in which multiple sclerosis and inflammatory polyneuritis occurred separately, and suggest that this association supports the idea that the two conditions may have an aetiological link.

Current medical speculation on the aetiology of multiple sclerosis includes the theory that viruses, and in particular the measles virus play some part in its pathogenesis (Fraser, 1977). In order to explain the peculiar susceptibility of some individuals to what may be regarded as a delayed complication of a common viral infection it has been suggested that both immunological (Hughes, 1977; Goust et al., 1978) and genetically determined mechanisms (Sachs, 1977) may be involved.

The Guillain-Barré type of polyneuritis is a well-recognised inflammatory demyelinating disorder of the peripheral nervous system, but virological studies have not yet shown any single virus to be responsible for all cases. Again one asks why only certain patients should manifest this complication of common viral infection, and it is possible that in these cases genetic or immunological susceptibility of the myelin may be the key factor.

We should like to describe two patients recently under our care who, on clearly separate occasions, seemed to show features of both inflammatory polyneuritis and multiple sclerosis.

\section{Case reports}

CASE 1

A 46 year old male lorry driver (GB) presented in June 1971. Three weeks previously he had developed acute right sided pleuritic chest pain which subsided spontaneously during the following week. In the week before admission to hospital he had an episode of sharp midthoracic back pain followed by paraesthesiae and numbness in the extremities of all four limbs, spreading

Address for reprint requests: Dr R. G. Lascelles, Department of Neurology, Manchester Royal Infirmary Oxford Road, Manchester M13 9WL.

Accepted_28 March 1979 gradually to the elbows and knees. His walking deteriorated steadily. There was no relevant past or family history, and no history of drug ingestion or vaccination. Examination on admission revealed a flaccid paraparesis with a glove-and-stocking type of sensory loss, total areflexia, and flexor plantar responses. Analysis of the CSF showed a protein of $3.75 \mathrm{~g} / 1$ with a normal cell count and glucose level. The Wasserman reaction was negative. The diagnosis of the Guillain-Barré type of polyneuritis was made, and he was given a 10 day course of ACTH gel.

He improved steadily, and when discharged from follow-up in July 1972 he was feeling well, had gone back to work, and had no abnormal neurological findings apart from the fact that his ankle jerks were still absent.

Five years later, in December 1977, the patient? was seen again. During the previous three months he had experienced bouts of vertigo, bilateral blurring of vision, loss of balance, and slurring of speech, lasting two or three minutes and occurring about once a month. These paroxysmal brainstem disturbances continued with increasing frequency over the next eight months. Clinical examination in January 1978 was normal. An EEG and technetium brain scan were normal but CSF examination showed a raised protein of $0.74 \mathrm{~g} / 1$ with a normal cell count and glucose content. In July 1978 he had two transient episodes of weakness of both legs and one of paraesthesiae in the hands, each lasting less than 24 hours, and when in August 1978 his brainstem symptoms recurred, and persisted for three days, he was readmitted.

Examinations revealed an incomplete right oculomotor paresis, with pronounced bilateral horizontal and vertical nystagmus, dysarthria, and ataxia. The tendon reflexes were all present apart from the ankle jerks, abdominal reflexes were absent, and the plantar responses extensor. The 
CSF protein content was $0.35 \mathrm{~g} / 1$, the IgG total protein percentage being $19.1 \%$ (IgG level $0.067 \mathrm{~g} / \mathrm{l}$ ) with a normal cell count and glucose content. We felt that this clinical picture could be explained only in terms of brainstem demyelination of the type seen in multiple sclerosis (Andermann et al., 1959; Espir et al., 1966).

He was treated with ACTH gel with considerable benefit. When reviewed in November 1978 he had had no further attacks and his abnormal signs were less marked.

\section{CASE 2}

A 49 year old male engineer (AE) was first seen in the orthopaedic department of the Manchester Royal Infirmary in March 1978. Seventeen years earlier and again 15 years earlier he had two episodes of a sensory disturbance in both legs each lasting two weeks and followed by full symptomatic recovery. For four years he had experienced heaviness of the legs on exertion, and for two years a feeling of constriction of the feet.

Examination in March 1978 revealed a spastic quadriparesis, generalised increase in tendon reflexes, absent abdominal reflexes, and extensor plantar responses. Myelography proved to be normal but examination revealed 9 lymphocytes per $\mathrm{mm}^{3}$. Protein content was normal at $0.25 \mathrm{~g} / 1$. The Wasserman reaction was negative. It was felt that this must be an example of multiple sclerosis. The patient declined treatment and was allowed home with no changes in symptoms or signs.

In June 1978 he developed a severe upper respiratory infection which resolved without therapy. Three days later pain and paraesthesiae began in all four extremities and extended gradually upwards to the elbows and knees. His walking deteriorated, and his balance was severely affected. He was referred again to our department, and examination then revealed a quadriparesis, flaccid as opposed to the previous spasticity, and the weakness was much more pronounced than previously. A glove-and-stocking sensory loss was found and he also had marked impairment of joint position sense in all four limbs. The tendon reflexes were all absent and the plantar responses non-reactive. Analysis of the CSF showed a normal cell count and glucose content. The protein concentration was $0.35 \mathrm{~g} / \mathrm{l}$. The diagnosis of acute polyneuritis was made but once again he refused treatment. Over the next two weeks he improved steadily and his tendon reflexes returned to their previously hyperactive state. When reviewed in November 1978 his symptoms and signs were those of his initial admission except that his plantar responses were flexor. A repeat CSF examination showed a normal total protein content of $0.25 \mathrm{~g} / 1$ but the IgG of $0.078 \mathrm{~g} / 1$ gave an abnormal $\mathrm{IgG} /$ total protein ratio of $31 \%$.

\section{Discussion}

The clinical features of these two patients indicated that they had suffered acute inflammatory demyelination of the peripheral nervous system with a good recovery and also demyelination of the central nervous system clinically akin to multiple sclerosis, on clearly separate occasions.

An association between the conditions was first described by Wartenberg (1958). Keuter (1967) described three such patients but emphasised that the clinical features of the polyneuritides were atypical in all the cases.

A recent editorial in the Lancet (1978), discussing the outbreak of Guillain-Barré polyneuritis after swine influenza vaccination, was followed by a letter from Morris and Young (1978), drawing attention to five cases diagnosed as multiple sclerosis with onsets closely related to swine influenza vaccination and suggesting a possible relationship between the two conditions.

Rosenblum et al. (1966) discussed the association between central and peripheral nervous system myelin affection, and Schoene et al. (1977) suggested the possibility of a common pathogenesis and pointed out that their first case showed sensitivity both to CNS myelin basic protein and to peripheral nerve antigen.

We wish to add our two cases to those already recorded and to make the additional point that in our patients there was clear evidence of inflammatory polyneuritis with a good recovery which apparently occurred quite separately from the coexisting central condition.

We would like to thank the late $\mathrm{Dr} \mathrm{L}$. A. Liversedge and Professor P. K. Thomas for their helpful comments.

\section{References}

Andermann, F., Cosgrove, J. B. R., Lloyd-Smith, D., and Watters, A. M. (1959). Paroxysmal dysarthria and ataxia in multiple sclerosis-report of two unusual cases. Neurology (Minneapolis), 9, 211215.

Espir, M. L. E., Watkins, S. M., and Smith, H. V. (1966). Paroxysmal dysarthria and other transient neurological disturbances in disseminated sclerosis. Journal of Neurology, Neurosurgery, and Psychiatry, 29, 323-330. 
Fraser, K. B. (1977). Multiple sclerosis: a virus disease? British Medical Bulletin, 33, 34-39.

Goust, J. M., Chenais, F., Carnes, J. E., Hames, C. G., Fudenberg, H. H., and Hogan, E. L. (1978). Abnormal $\mathrm{T}$ cell subpopulations and circulating immune complexes in the Guillain-Barré syndrome and multiple sclerosis. Neurology (Minneapolis), 28, 421-425.

Hughes R. A. C. (1977). Immunological aspects of multiple sclerosis. British Journal of Hospital Medicine, 18, 467-476.

Keuter, E. J. W. (1967). Polyneuritis and multiple sclerosis. Psychiatria, Neurologia, Neurochirurgia, 70, 271-279.

Lancet (1978). Editorial. Lancet, 2, 243.

Morris, J. A., and Young, B. G. (1978). Guillain-Barré syndrome. Lancet, 2, 636.

Rosenblum, W. I., Budzilovich, G., and Feigin, I.
(1966). Lesions of the spinal cord in polyradiculoneuropathy of unknown aetiology and a possible relationship with the Guillain-Barré syndrome. Journal of Neurology, Neurosurgery, and Psychiatry, 29, 69-76.

Sachs, J. A. (1977). HLA antigens in multiple sclerosis. Proceedings of the Royal Society of Medicine, 70, 869-871.

Schoene, W. C., Carpenter, S., Behan, P. O., and Geschwind, N. (1977). "Onion bulb" formation in the central and peripheral nervous system in association with multiple sclerosis and hypertrophic polyneuropathy. Brain, 100, 755-773.

Wartenberg, R. (1958). Neuritis, Sensory Neuritis, Neuralgia: A Clinical Study with Review of the Literature, pp. 296-305. Oxford University Press: New York. 